thermostatic control is fitted. Presumably a baby suffering from artificial heat-stroke would have the symptoms of dehydration fever, and the cause of death would be " prematurity." Too great a weight of blankets on the infant's cot may possibly be a cause of fatigue of the respiratory muscles-and death. The zealous, harassed, but inexperienced mother should be warned of this risk. Is the danger fully realized ?

Though, as already stated, I have not yet seen in print any expression of approval of my suggestion to have this matter thoroughly and conscientiously investigated, obstetric specialists in centres in this country and as far afield as Australia have expressed their complete agreement with my remarks. The surprise and disappointment of 'being ostracized on account of these letters by some with whom I had worked most happily for many years have been compensated by the (to me) unknown "feckless," anaemic, and frail little woman living under slum conditions, who had seen an extract of my letter in the lay Press, telling me that she had had no further trouble with her ailing baby after heeding the suggestion and abandoning the tight wrapping she had been taught.

Much of this may seem irrelevant as far as Dr. Lewis's article is concerned, but as the object of all of us is to save these precious lives I appeal once more to all doctors and nurses to satisfy themselves beyond all doubt that the infants under their care are not being slowly suffocated in the way described.I am, etc.,

Huddersfield.

S. H. WADDY.

\section{Periarteritis Nodosa}

SIR,-I was interested in Dr. L. M. Shorvon's case of periarteritis nodosa (May 3, p. 601). The difficulty of making this diagnosis during life lies in the diversity and the frequently changing character of the physical signs and symptoms in this condition. But it is just the great variety of the clinical picture e.g., fever of the remittent type, tachycardia, polyneuritis, polymyositis, albuminuria and cylindruria, asthmatic attacks with bronchitis, hypertension, and leucocytosis with blood-eosinophilia-which is suggestive of periarteritis nodosa. The conception of periarteritis nodosa being the result of an extreme degree of vascular allergy has found wide recognition in recent years. It therefore seems doubtful whether this condition represents a disease entity but rather belongs to the wider group of diseases caused by the anaphylactic hyperergic reactions-e.g., Loeffler's syndrome, angioneurotic oedema, tropical eosinophilia, and probably rhemmatic fever. The principal difference of these conditions lies in the intensity and extent of the vascular involvement. In a recent publication of two cases of periarteritis nodosa (A. Elkeles and L. E. Glynn, Brit. J. Radiol., 1944, 17, 368) we showed in serial radiographs of the chest the occurrence of transitory infiltrations in the lungs during the early stages of the disease. These were later superseded by persistent and progressive damage to the pulmonary vessels and bilateral pleural effusion. The presence of transitory as well as persistent and progressive changes in the lungs, with concomitant blood eosinophilia and the severe clinical picture, made a correct diagnosis possible during life. Transitory pulmonary infiltrations and blood eosinophilia are also met with in Loeffler's syndrome ; but here the clinical picture is characterized by a mild course, and the lung infiltrations usually disappear completely within a few days, although in rare instances migratory pulmonary lesions may persist for several months.

In contrast to the striking radiological findings, physical signs of the lungs in Dr. Shorvon's case and in our cases were scanty and even absent. That is why little attention has been paid so far to the pulmonary changes in this condition, which, however, as shown by serial $x$-ray examination, may provide an important clue to this notoriously difficult disease.-I am, etc.,

London, W.1.

A. Elkeles.

\section{Heroin and Pethidine during Labour}

SIR,-I would like to express appreciation of the scholarly paper by Miss Josephine Barnes (April 5, p. 437) on the use of pethidine in labour. Pethidine is certainly a safe drug to use and has many advantages. It has one very serious disadvantage, however, and that is that its action is unreliable. In Miss Barnes's series good analgesia was obtained in only $55 \%$ of cases, a figure in accord with my own much smaller experience of pethidine.

There is one drug, however, which is vastly superior to pethidine, and that drug is heroin (diamorphine hydrochloride). In analgesic effect heroin is much more powerful than pethidine, and its action is very much more reliable. When properly used it does not interfere with the normal course of labour and, as I have already shown in a previous communication (Jan. 8, 1944 , p. 59), it can be safely given in full doses at any time during labour.

With experience one varies the dose according to the type and frequency of the contractions and the degree of dilatation of the cervix, but as a general guide one would say that $1 / 6 \mathrm{gr}$. $(10.8 \mathrm{mg}$.) should be given when the cervix is three fingers dilated and a further $1 / 12$ or. $(5.4 \mathrm{mg})_{\text {i }}$ just before full dilatation. If the cervix is almost fully dilated or the second stage has already commenced when first seen one would give the full dose of $1 / 6 \mathrm{gr}$. $(10.8 \mathrm{mg}$.) straight away. It is important not to give heroin too soon in the first stage, or else uterine action will be damped down. In this respect heroin differs from pethidine, which can be given earlier in labour. In those cases where the contractions are weak and some degree of uterine inertia is present I prefer to give pethidine rather than heroin.

When heroin is given in adequate doses, supplementary anaesthesia at the end of the second stage is not always required. When it is deemed necessary, a little chloroform or gas and air can be administered. For certain cases, particularly breech delivery, I find pudendal block very efficacious.

There are of course other aspects of the prevention and relief of pain in labour apart from the administration of analgesic drugs, and it is important not to neglect them. For example, there is the overcoming of fear and tension, and there are those measures designed to promote flexibility of the pelvic joints during pregnancy. The actual method which one employs to relieve pain in labour is probably of secondary importance. What is far more important is that everyone should master some method and apply it conscientiously. There is, unfortunately, far too much apathy and indifference among those who undertake maternity work. To make no attempt to relieve pain in labour, or to make only a half-hearted attempt, is a sign of slackness and a public confession of mediocrity.-I am, etc.,

Troon, Ayrshire.

JAMES RosS.

\section{Artificial Insemination}

SIR,-In the answer to a correspondent's inquiry about the technique of artifical insemination ("Any Questions," May 3, p. 625) you conclude: "Finally, attention should be drawn to the medico-legal aspects of this procedure," and refer him to a leading article on the subject in the same issue. While conceding that the leading article was intended to cover only a special aspect of the subject, I feel strongly that the answer should have included an admonition about the psychological as well as the medico-legal aspects. As your leading article points out, the legal status of the procedure and its consequences are still beset by doubts, but even a lay person unacquainted with formal psychology can hardly doubt that serious psychological dangers threaten all those who accept artificial insemination.

It is the clear duty of doctors and psychologists to point out the formidable hazards to happiness and peace of mind which confront all who resort to this expedient. The vital human factors, which should outweigh all other considerations, have received a minimum of attention or have been ignored as matters of small moment compared with the technical problems involved.

It is a fact that couples who request artificial insemination constitute a cross-section of psychological types. It is, moreover, by no means easy for even an expert psychologist to predict with confidence that any couple will not eventually experience strong emotional reactions which may become increasingly intense as the years pass. The manifold and ineradicable psychological difficulties which might wreck the lives of the woman who accepts A.I.D., her husband, and the "testtube" child will be evident to anyone who gives the subject a moment's thought. However eagerly she may have resorted to the method in her desire for a child, the woman sooner or later is likely to experience a vague feeling of dissatisfaction with herself-what we might almost term a sense of sin, af 
taint, or unwholesomeness. In spite of herself she is almost sure to indulge in morbid musings about the unknown father of her child, and she may tend to grow away from the husband who played no part in the deepest experience of her life. The husband, whose self-esteem was dealt a shattering blow by the mere revelation of his sterility, cannot help but consider the child a constant reminder of his "inferiority," and in time he may come to hate it and hotly to resent the attention which his wife lavishes on it. The child, an ambiguous figure at best, will be the most pitiful victim of these and other devastating and uncontrollable emotional consequences, which, to date, have received far too little consideration.

In the past I have administered both types of artificial insemination, but as a result of experience and reflection I would not now take any case except one in which the husband was the donor. I think it essential that all doctors, whatever their views, should present the psychological objections to their patients in the strongest terms.-I am, etc.,

London, W.1.

Eustace Chesser.

\section{Complete Abortion without Initial Vaginal Bleeding}

SIR,-The following case is of interest on account of the rarity of abortion occurring without warning uterine bleeding.

The patient, a para-3 aged 28, was seen in her own home on account of severe upper central abdominal pain of four hours' duration. The pain was colicky in nature, did not radiate, nor was it accompanied by vomiting, but was made worse by movement and deep breathing. Her personal history revealed the fact that she had been severely constipated for eight days and that she had not had a "proper" menstrual period for three months, although there had been some staining at the usual date of her period during this time. There was no history of previous abdominal colic.

On examination she did not look ill, temperature was $98^{\circ} \mathrm{F}$. $\left(36.7^{\circ} \mathrm{C}.\right)$, pulse 100 , and there was generalized tenderness over the abdomen most marked in the right iliac fossa but without definite guarding. The rectum was loaded with hard faecal masses. Vaginal examination showed the uterus to be enlarged consistent with a 12- to 14-week pregnancy. There was no blood on the examining fingers nor on the vulva. The urine contained no gross abnormalities nor were there any physical signs in the chest.

Two soap-and-water enemata were given with good result and some relief of pain. Conservative treatment and observation was considered advisable and suitable. Next day the pulse had settled to 80 , but there was still tenderness in the right iliac fossa, and the rectum was still loaded with faeces. Two further enemata were given with good result, so that the patient was free from pain on the third day.

On the fourth day of her illness the patient experienced a recurrence of mild-colicky generalized abdominal pain indicating, as she thought, the need to use the bed-pan. Into the latter she passed a complete foetus of about 14-weeks size, along with a small blood clot. This blood was the only haemorrhage seen during the numerous visits paid to the patient. Recovery has been uneventful following curettage, when only a small amount of blood clot was removed.-I am, etc.,

Larne. Co. Antrim.

H. E. RUTHERFORD.

\section{Child Guidance}

SIR,-Dr. Ian Skottowe in his letter (May 3, p. 616) speaks of (1) " the unnecessary confusion that there is on this subject," (2) "mental illness in children." The use of the term "mental illness" doesn't help much.

Most of the authorities are not agreed. The Association of Education Committees have recently stated that the educational psychologist should be in charge of child guidance clinics and not the psychiatrist. If we do as Dr. Skottowe suggests and "leave the matter there" the education departments with the psychologist in charge of the "centre" (and the psychiatrist an indispensable lackey) will have control of the "treatment" of most maladjusted children, delinquents, etc., while the medical department will be expected to deal with what ? Mental illness? Psychotics, amounting to about $\frac{1}{2} \%$ of children requiring psychological treatment? Or just the rejected enuretics and some encopreses?
In the meantime the Ministry of Education expects the medical department of the local authority to certify on the appropriate form the fate of educationally subnormal pupils (a definition of which is based not on the I.Q., by the way, but on the standard of achievement in the basic subjects). What sort of topsy-turvy chaos will exist? Dr. Skottowe may or may not know that in one of the Home Counties the educational psychologist is arranging all the child guidance clinics through the education department. If the medical department sets up "mental illness" clinics there will certainly be two administrations dealing with the children requiring psychological treatment.

I repeat my previous contention-namely, that where the school training (with the educational psychologist advising the chief education officer) has failed to prevent a child reaching a child guidance clinic or centre the child's problem is both psychological and clinical-psychological for obvious reasons which nobody denies, and clinical because in most cases there is a parental problem which should not be dealt with by a lay worker. For that reason all psychological misfits which the schools cannot deal with should be in the first instance directed to the school medical department. I am forced to this conclusion not through any motives of "will to power". for my faculty but sincerely in the belief that the educational psychologist, although far ahead of the psychiatrist in the technical armamentarium and skill of his profession, is nevertheless quite unfit to appreciate more than the surface of the parental problems. If by mental illness Dr. Skottowe (and for that matter the Ministry of Health too) means all psychological misfits, then Dr. Skottowe and I have no argument between us.

I disagree altogether with his dislike of the syntax of the term "child psychiatrist." $\mathrm{He}$ is just allowing his imagination too much scope. Is a child lover necessarily a minor ? A bird watcher an animal ? Or a rabbit hutch a rabbit ?-I am, etc.,

Kingston-on-Thames.

John A. McCluskie.

${ }_{*}^{*}$ This correspondence is now closed.-ED., B.M.J.

\section{Nicotinamide and Diabetes Mellitus}

SiR,-I was very interested to read Dr. H. J. Wade's article on nicotinamide and diabetes mellitus (March 29, p. 414). I have been working on the subject for the past year and have published a preliminary report on thirty cases in the Journal of the Royal Medical Association of Egypt, 1947, 30, 29. I found that $60 \%$ of the cases of diabetes, mostly in the mild and moderate group, and a few in the severe group, do well on this form of therapy, as shown by the sugar-tolerance curves. Those that do not show any or only slight response are the juvenile diabetics, and some of each of the above groups, mostly the severe ones. Even in these cases the insulin requirements may be decreased.

I would like to point out that I used the same dosage as Dr. Wade, but that it takes four to six weeks to show any appreciable response and up to six months to show optimum response. I suggest that Dr. Wade did not follow his six cases sufficiently long, and that their number is inadequate for any conclusion.-I am, etc.,

Cairo, Egypt.

Said M. Talant.

\section{Safety in Electric Convulsion Therapy}

SiR,-The letter from Dr. R. A. Sandison (April 26, p. 579) is very important to me and, I hope, to many others. It could reopen the long and somewhat acrimonious correspondence which you received about anaesthesia, and it emphasizes the dangers of elaborating what should be a simple procedure. I have been forced by circumstance to be an anaesthetist, and am by inclination a psychiatrist. In both of these specialties I feel that the "human" element is disappearing, and the patient is now becoming a piece of physiological apparatus.

Some time ago I read in the Journal of a Service woman who had died during an operation for an "interval " appendix. She had received thiopentone to prevent her being upset by a spinal anaesthetic which had to be supplemented by gas and oxygen. One was left with the impression that any feeling about the summation of all those anaesthetics having been connected with the cause of death had been satisfactorily rationalized. 